Gunther and Rayner' had found previously, off Peru.

The physical and chemical results will be published shortly by the National Institute of Oceanography in the 'Discovery' Reports, and further studies are being made of some of the problems which have been mentioned with the particular object of obtaining evidence about the factors which affect oceanic productivity. ${ }^{1}$ Defant, A., "Das Kaltwasserauftriebsgebiet vor der Küste Süd-
westafrikas" Landerkdl. Forsch., Festchr. N. Krebs., $52(1936)$.

"Sverdrup, H. U., et al. "The Oceans" (Prentice-Hall Inc., New

${ }^{3}$ Wüst, G., Wiss. Ergebn. dtsch. atlant. Exped. 'Meteor', 6, Teil 1, 123 (1936).

" Sverdrup, H. U., J. Mar. Res., 1, 155 (1938).

${ }^{5}$ Defant, A., Dtsch. Hydrogr. Z., 5, 69 (1952).

${ }^{6}$ Cooper, L. H. N., J. Mar. Biol. Assoc. U.K., 23, 181 (1938).

'Marchand, J. M., Special Rep. No. 5, Fish and Mar. Biol. Surv., Union of S. Africa, Rep. No. 6 (1928). Copenhagen, W. J., Fis No. $3(1934)$.

${ }^{8}$ Brongersma-Sanders, M., Verh. Akad. Wet. Amst., 2nd Sect., DL. 45, No. 4 (1948).

' Gunther, E. R., Discovery Reports, 13, 107 (1936).

\section{MAGNETIC PROPERTIES OF ROCKS}

$\mathrm{T}$

HE significance of the natural remanent magnetism of igneous and sedimentary rocks has not yet been determined. On one hand, there is the hypothesis that the direction of magnetization can be interpreted in terms of a widely varying magnetic field and, on the other, that the adverse polarizations arise from intrinsic properties of the rock assemblage. These aspects formed the main theme of a geophysical discussion at a joint meeting of the Royal Astronomical Society and the Geological Society, held in London on January 23, with Prof. E. C. Tilley (Department of Mineralogy and Petrology, Cambridge) in the chair. Prof. Tilley noted that the magnetic properties of rocks have also been found to be of considerable value to goologists by yielding magnetic anomalies reflecting the distribution of certain rock-types, the measurement of such anomalies culminating in aeromagnetic surveys.

In opening the discussion, Dr. J. M. Bruckshaw stated that the value to the geologist of the results he proposed to discuss would be controlled by their final interpretation. Of recent years the study of permanent rock magnetism has been intensified, and Dr. Bruckshaw's interest was first aroused by the discovery that the tholeiite dykes of northern Fngland are magnetized in a direction opposite to that of the present earth's field. Since these dykes represent the final phase of igneous activity centred upon Mull, it was an obvious step to examine the rocks in the earlier phases of this activity. The earliest phase was the quiet extrusion of a sequence of lava flows followed by the cyclic intrusion of basic and acid ring dykes and cone sheets about a centre which migrated twice towards the north-west. The final phase was the production of the north-west dyke swarms, of which the tholeiite dykes were the last members. Since a known time-sequence of events exists, it is possible to sample rocks of different periods and, in the present case, some of the basalt flows, some early basic intrusions, the ring dykes of Glen More and Loch Bà and some of the north-west dykes were examined. After a rock has been polarized, many factors may tend to modify it, and some influences will result in random magnetization. For example, a partially solidified lava-flow might be broken up by a further supply of lava. Thus a number of specimens from each formation must be examined, and they usually show a scatter of directions. Inspection may be sufficient in some cases to determine if the mean direction has a significance, but the probability that the observed set of directions can be selected from a random distribution is used for indicating what weight can be attached to the mean direction; the smaller the probability the more significant the mean direction.

Using those formations associated with significant directions, the basalt flows proved to be adversely magnetized and also the early basic intrusions. The more acid ring dykes of Glen More and those of Loch Bà were normally magnetized; but a dolerite dyke, earlier than the Loch Bà granophyre, proved adversely magnetized. The dykes of the north-west swarm were normal, and to this must be added the adverse phase of the tholeiite dykes, giving a total of three adverse phases.

The large observed intensities of magnetization in relation to the earth's magnetizing field can only be explained in terms of thermoremanence acquired during the initial cooling, the only occasion when the present rocks were at the necessary high temperature. If this is accepted, the amazing stability of this polarization follows; and laboratory observations support this conclusion, the coercive force of the rocks being comparable with that of modern magnetsteels. In all respects the rocks exhibited ordinary magnetic properties under a variety of conditions and, in particular, acquired normal polarization when cooled in the earth's field. It would thus appear that the simplest explanation of the facts is a number of reversals of the earth's magnetic field in the past, a suggestion to which there are no theoretical objections.

Mr. K. M. Creer pointed out that the main evidence on adverse magnetization comes from igneous rocks, which are magnetized either normally or at $180^{\circ}$ to the normal direction. Although there are no theoretical objections to a reversal of the earth's polarity, other explanations of adverse magnetism are possible, such as those suggested by Neel. One of these assumes a constituent having a spinel structure in which two sub-lattices exist, one tetrahedral and the other octahedral. The spontaneous magnetic vectors associated with the sub-lattices have opposite directions and, in suitable conditions, the resultant magnetization would change sign with temperature, thus allowing adverse polarity. This property of imperfect antiferromagnetism is not known. Another process involves two magnetic constituents with widely differing Curie temperatures. On cooling, the constituent of higher Curie point is first magnetized and produces a demagnetizing field. Due to its large negative temperature-coefficient, the initial intensity grows rapidly and the demagnetizing field ultimately exceeds the original field at the Curie point of the second constituent, which becomes adversely magnetized. The ferromagnetic constituents must occur in aggregates of high local concentration.

Mr. Creer recorded that a hypersthene hornblende dacite discovered by Nagata does exhibit adverse magnetization when cooled in a weak field. From it, two magnetic constituents have been separated by Dr. G. D. Nicholls, of the University of Manchester. One (probably magnetite) behaves normally, but the other shows reversed thermoremanent magnetism. He suggested that the normal behaviour of naturally 
adversely polarized rocks in the laboratory could be attributed to the rapid rate of cooling, when the components required by Néel do not have time to exolve.

Finally, Mr. Creer considered the evidence of sediments which, on Néel's theory, should not possess inverted magnetism. In the Appalachian Mountains, adversely magnetized Silurian sediments are interbedded with similar but normally magnetized sediments, and these are contemporary, as revealed. by the presence in both sets of ostracods of short-time duration, with flat-lying and normally magnetized sediments outside the geosyncline. Thus, any field reversal must have been of a local character, and the reversed sediments in the geosyncline may be the result of a complex history during the mountainbuilding orogeny. Certain physical differences between the sets of sediments suggest a second interpretation that the polarization of the geosynclinal sediments is stable, but in the flat-lying beds it has, on the whole, followed the subsequent changes in the earth's field. In fact, the absence of any widespread reversals in sediments may be due to instability. Graham's experiments on sediments over a wide time-range show that the most frequent direction of magnetization agrees with a normal dipole field, while conglomerates, which should exhibit random magnetization of the pebbles, show a systematic direction agreeing closely with the present field.

The testing and use of magnetic-survey methods by H.M. Geological Survey and Museum was outlined by Dr. A. F. Hallimond. The problem of the correlation between the observed anomaly and that computed for the structure was initially examined in 1929 by a magnetic survey over the Swynnerton Dyke in Staffordshire; but certain aspects of the interpretation of the field observations proved difficult, since the anomaly due to the splitting of the dyke into two branches gave results similar to that over a dyke with concentrations of magnetite near its flanks. In the simpler cases, however, the observations conformed with theory. Later work over the Lornty Dyke at Bairgowie in Perthshire gave a totally different anomaly from that predicted on the basis of its induced magnetism due to abnormal permanent magnetism. Just before the Second. World War, it was demonstrated, in association with Prof. J. T. Whetton, that shallow deposits of weakly magnetic hæmatite could be located by their associated magnetic field. Among others, investigations were carried out over the Brockhill Dyke (Worcestershire) and also in Teesdale over faults in the Whin Sill. The former resulted in the tracing of the extensions of the dyke to the east and west, but estimates of width were rendered difficult bocause of the appreciable width of the adjoining, and magnetically altered, sediments. Two well-defined faults were followed in the Whin Sill and, in addition, observations over two outcrops, with strikes roughly parallel to and at $45^{\circ}$ with the magnetic meridian, permitted the rough resolution of the permanent and induced intensities. The measurements were compatible with an induced polarity based on a susceptibility agreeing with direct observation, together with a horizontal permanent intensity directed approximately due south. The value of magnetic observations as an aid to geological investigations has been fully confirmed by the tests.

Mr. J. Hospers stated that his experiments support the suggestion of a reversed field, rather than that of some property of the rock, to account for adverse magnetism. In Iceland the examination of historical flows between A.D. 1766 and 1948 gives a mean direction of magnetization making an angle of $7^{\circ}$ with the present field and $1^{\circ}$ with an axial dipole field, and post-glacial flows, between two and six thousand years old, have a mean declination of $1 \cdot 1^{\circ}$ and a dip of $73.8^{\circ}$ downwards, very near the dipole field. On the other hand, Early Quaternary flows, of a million years old, have a mean direction making an angle of $8^{\circ}$ with the opposite direction of the present field. Below these there is a zone of normally magnetized Tertiary lavas followed by zones of alternate adverse and normal magnetization. The picture revealed is consistent with the idea of a sequence of field changes, occupying about ten thousand years, followed by a period of steady conditions, either normal or adverse, for some half a million years. It was emphasized that the polarization of sediments between the flows conforms with that of neighbouring flows.

This conclusion is supported by the behaviour in the laboratory of rock specimens when heated and cooled. A rock, possessing adverse magnetization assumed to have been acquired by Néel's twocomponent mochanism, when heated should show a reduction in intensity as the temperature approaches the lower Curie point of the two constituents and, at, some temperature just below this critical point, the reduced adverse polarization should be balanced by the normal polarization of the constituent of high Curie temperature. At the lower transition temperature the normal polarization only would operate, and this would finally fall to zero at the higher Curie point. Thus, the curve of intensity against temperature should show a reversal of polarity, a behaviour which was, in fact, observed for the dacite discovered by Nagata. Both normally and adversely magnetized specimens from Iceland, however, exhibit a monotonic fall to zero with increasing temperature, with no evidence of a reversal. 'Thus, Néel's twocomponent mechanism cannot apply. Some curves suggest two similarly magnetized constituents of differing Curie temperatures. On cooling in the laboratory field, each specimen recovers its polarization, the cooling curve matching closely the heating curve, a behaviour consistent with the hypothesis of a field reversal.

Prof. Tilley read a contribution from Prof. A. F. Buddington (Princeton University) in which some extensive negative anomalies, revealed by an aeromagnetic survey of the north-western Adirondacks, were discussed. Specimens of the gneisses, with which these anomalies are associated, possess inverse polarization in all cases, and this appears to be related to the ilmeno-hæmatite or titaniferous hæmatite in the rocks. The literature shows the presence of hæmo-ilmenite, titaniferous maghæmite and other similar minerals in rocks possessing adverse magnetization, and the general conclusion is that these minerals, with abnormal magnetic properties, are responsible for the phenomenon. The fact that magnetite, contemporary with these, often possesses normal polarity adds weight to this conclusion. No inference concerning the earth's magnetic field can thus be made until the possible significance of these minerals has been ascertained, the identification of the minerals requiring $\mathrm{X}$-ray, chemical and microscopic examination.

The general discussion was opened by Sir Lewis Fermor, who described some of his early experiences 
in the Central Province of India during 1906, following the discovery that certain manganese minerals were magnetic. A dip needle gave very different readings over manganese ores and over the adjoining gneisses and schists. Due to a defect in the instrument, a systematic survey was not made and the observations were not published. Nevertheless, it was of interest to note that the Geological Survey of India had employed successfully the magnetic method in the search for manganese. Referring to the production of adverse magnetization by the processes suggested by Néel, Dr. S. A. Vincenz stated that the first need not be discussed since no such substance is known; but the second process is feasible. The latter is based upon the presence of two constituents, of differing Curie points, and their concentrations in aggregates or "amas". Using the formula developed by Néel and the observed properties of the Mull rocks, the required concentration in the aggregates can be determined. For the lavas and the olivine gabbros, these prove to be 42 per cent and 58 per cent, respectively, and he asked if there is any evidence for a distribution of ferromagnetic minerals in concentrations of this type. Dr. Vincenz also stated that the Swynnerton Dyke possesses remanent magnetism perpendicular to the present field, and similar results have been observed in some Tertiary Welsh dykes. It was pointed out by Dr. H. Manley that only one rock shows adverse magnetism in the laboratory compared with the many hundreds which behave normally.

A remarkable anomaly, associated with a dolerite sill in New South Wales, was described by Mr. A. Day, in which comparable positive and negative centres occur. As titanium is found in the rock, he suggested that a microchemical analysis for titanium in the magnetite of abnormally magnetized rocks might be useful. A similar case in the Allard Lake District, Quebec, was cited by Prof. D. Williams, where massive ilmenite-hæmatite gives negative anomalies but disseminated ore gives positive anomalies. A plea for the examination of the accessory minerals was made by Dr. W. Bullerwell, who indicated that, in Mull, the acid rocks are all normally magnetized. He inquired if their magnetism is less stable than that of the basic rocks, but was informed that their behaviour does not suggest this. On this point Dr. J. Sutton said that valuable data might be obtained from the mixed acid and basic formations of Mull. Replying to a further question by Dr. Bullerwell, Mr. Hospers stated that his suggested time for a change in the field was not based on theory but on observations of consecutive lava flows.

Mr. F. Lowes showed that Graham's argument, repeated by Mr. Creer, which is based on two oppositely magnetized deposits that are contemporary on the basis of their fossil content, does not condemn the idea of a field inversion. A fossil may persist for a million years-a period sufficient to embrace a number of reversals. The discordantly magnetized Welsh Dykes may represent a period of change. Mr. $R$. Hide pointed out that sedimentary rocks might show the secular change in the past, and the direction of drift during a period of reversal would be an important factor in sustaining or condemning modern theories of the main field.

Summarizing, Prof. Tilley said that many outstanding questions still remain and further data are necessary on sediments and igneous rocks. In particular, a knowledge of the accessory minerals is ossential.

\section{OBITUARIES}

\author{
Prof. Philipp Ellinger
}

Philipp Ellinger died in London on September 12, 1952, after a long and painful illness. He was born in 1887 in Frankfurt am Main, where he spent his early years before proceeding to Munich to study natural sciences under von Bayer and Roentgen. He took the D.Phil. degree in chemistry at Greifswald under von Auwers in 1911, and passed on to Heidelberg to study medicine and finally graduated D.Med. in 1913. During the First World War he served as a medical officer in the German Army and returned after the cessation of hostilities to Heidelberg, where he occupied successively the position of assistant, lecturer and deputy director in the Pharmacological Institute there and served under three distinguished pharmacologists, Gottlieb, Wieland and Heubner. Towards the end of 1931 he was called to the chair and directorship of the Pharmacological Institute at the Medical Academy of Düsseldorf. By 1933, however, the political situation in Germany rendered his position untenable, and he found refuge in Britain, where, at the Lister Institute, he took up his research problems again and remained until his retirement in June 1952 .

Ellinger's early work was largely in the field of toxicology; but by the time he came to Britain he had already turned to physiology, had published important work on renal function and had invented a technique for intravital microscopy which employed fluorescent dyes. With Koschara in 1933 he worked on flavin pigments which he isolated from whey, and thus he contributed materially to the discovery and identification of lactoflavin (riboflavin) as a member of the vitamin $B$ complex and helped to establish the presence of this biologically important material as a constituent of Warburg's yellow enzyme. In 1937 he visited Egypt on behalf of the Medical Research Council to study pellagra, and returned to complete his investigations in 1938. During the second visit he became seriously ill and never fully recovered his normal health in after-years. As a result of the studies carried out in Egypt he concluded that the occurrence of pellagra resulted from two concomitant but independent factors. First, that a condition of latent pellagra arose from malnutrition, or malabsorption, due to the presence of intestinal infections. He believed that external factors such as hard physical work brought on an active pellagra when the latent state had developed. Ellinger examined the effects of a deficiency of different members of the vitamin B group on the excretion of abnormal porphyrin pigments, and just before the Second World War attempted to isolate and identify the lightsensitizing materials in buckwheat. Somewhat later (1942) he interested himself in the metabolism of nicotinamide in man and animals, and studied very thoroughly, during the next few years, the elimination of nicotinamide methochloride in normal and nicotinamide-deficient persons. The results of these researches revealed that the intestinal bacterial flora can form a very significant extra-dietary source of nicotinamide. His last investigations, on the heredity of the nicotinamide methylating mechanism in the rat and the elaboration of a new spectrophotometric method for tracing unknown urinary metabolites, remained unfinished.

Ellinger was highly cultured and widely travelled, and had many of the qualities of the typical German 